\title{
Parapharyngeal Lymph Node
}

National Cancer Institute

\section{Source}

National Cancer Institute. Parapharyngeal Lymph Node. NCI Thesaurus. Code C142302.

Any lymph node located in the potential space of the neck, which is bounded superiorly by the base of the skull, inferiorly by the greater cornu of the hyoid bone, anteriorly by the investing fascia of the deep cervical fascia covering the medial pterygoid muscle, posteriorly by the prevertebral layer of the deep cervical fascia, medially by the middle (pretracheal) layer of the deep cervical fascia, and laterally by the investing fascia of the deep cervical fascia covering the deep lobe of the parotid. 